\title{
This American life: in the key of C(ancer)
}

\author{
Malignant: How Cancer Becomes Us \\ S. Lochlann Jain \\ University of California Press; 2013
}

A s I began writing this review, the British Medical Journal had just published, "Twenty-five year follow-up for breast cancer incidence and mortality of the Canadian National Breast Screening Study: randomised screening trial." ${ }^{\text {The study's }}$ conclusions are now widely known: screening mammography does not decrease mortality from breast cancer in women aged $40-59$ and $22 \%$ of screendetected invasive breast cancers are overdiagnosed.

The possibly empty promise of (some) cancer screening is but one of the many controversial issues tackled by S. Lochlann Jain, a Canadian-born anthropologist at Stanford University, California, who was given a diagnosis of late-stage breast cancer in her thirties. Part cancer memoir, part examination of a disease that has metastasized into the social, economic, scientific and cultural substance of American life, Malignant is a tour de force, which deserves a wide readership in Canada.

The public, Jain believes, needs a more comprehensive understanding of cancer beyond the physical entity of the disease and the search for its cure. Cancer, she says, is a "constitutive aspect of American social life, economics, and science." Half of all Americans will be given a diagnosis of invasive carcinoma: from the economic point-of-view, cancer is a multibillion dollar business. She writes that the National Cancer Institute reports the medical costs of the disease in the fiscal year 2011/12 totalled $\$ 125$ billion. As the author puts it, "a culture that has relished dazzling success in every conceivable arena has twisted one of its staunchest failures into an economic triumph." These numbers rattle
Malignant
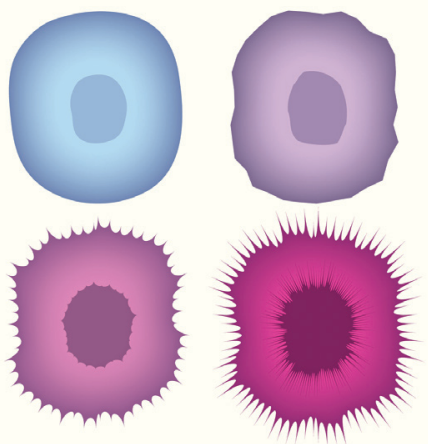

How Cancer Becomes Us

$$
\text { S. Lochlann Jain }
$$

up against the fact that up to 45 million Americans, Jain tells us, remain uninsured while up to $60 \%$ of personal bankruptcies in the United States result from the high cost of health care.

Culture at large has retreated to the feel-good tactics of rides, walks, runsfor-the-cure while demanding that those with cancer "stay positive." Or, as the author puts it, "[c]ancer is about the way U.S. culture shrouds terror under a scarf of rosy hopefulness."

Attitudes have evolved, but still, society finds a way to distance itself by blaming the victim and stigmatizing. No wonder women go to great lengths to disguise their breast cancer status by wearing wigs and breast prostheses?

Despite the huge investment in cancer research, Jain points to the gaps. We learn that there have never been longitudinal studies of cancer rates among in vitro fertilization egg donors, women whose bodies are unnaturally ripened with hormone treatments. Jain was one such donor and, given what we know about the use of diethylstilbestrol in the 1950 s and '60s and hormone-replacement therapy, it is indeed a puzzling omission in the scientific literature.
With an unflinching eye on corporate America, Jain divulges the dirt on firms that produce chemotherapeutic drugs and, at the same time, contribute to toxic dumps or churn out products such as potentially carcinogenic pesticides.

Closer to home for physicians, Jain writes that the randomized controlled trial has come to define the field of oncology. Clinical trials have become a "booming industry." Patients enrol in studies hoping a new agent will affect a cure. Here, quality of life and quality of death often collide. How much suffering is acceptable? "Unlike survival rates, treatment injuries and complications have no complex statistical methods to measure them," she writes.

I do have a quibble with the book, though. I would have preferred to read her cancer memoir in continuous chapters rather than finding it sprinkled throughout the book. Was she somehow afraid the personal would detract from the academic? If so, I think this concern was unfounded; the whole would have been better served if her personal story had been told more cohesively.

Nonetheless, Jain has read across disciplines and channelled the knowledge into a text that wakes us up from our reluctant acceptance of a disease that has wormed its way into everyday life. We can be thankful she used her cancer diagnosis as a catalyst for a powerful book that should surely generate some important debate.

\section{Brian Deady MD}

Clinical associate professor

Department of Emergency Medicine

University of British Columbia

Vancouver, BC

\section{Reference}

1. Miller AB, Wall C, Sun P, et al. Twenty-five-year follow-up for breast cancer incidence and mortality of the Canadian National Breast Screening Study: randomised screening trial. BMJ 2014;348:g366. 